\title{
In-Rush Current Mitigation on Toroidal Transformers with Composite Cores
}

\author{
W.P.T.S. Perera, J.P. Karunadasa, G.S.N. De Zoysa and \\ M.A.S.C. Wickramasinghe
}

\begin{abstract}
Toroidal transformers are high performance transformers used in high end applications. The unique toroidal construction drives them for such performance levels, but the gap less core construction itself makes them lag in controlling high inrush currents. Transformer based solutions are always favourable in the industry over the external solutions, but most of the existing transformer based solutions weaken the toroidal transformer's typical superior performance while mitigating the inrush current.
\end{abstract}

This paper investigates an effective inrush current mitigating method with composite cores, while protecting the performance level of typical toroidal transformers and being competitive in the market. The proposed method has two cores made with different steel types which are positioned concentrically, where the inner core is uncut, but the outer core is cut with an air-gap. This paper investigates on the optimum air-gap that should be maintained to minimize the inrush current based on the transformer size and the particular two steel types. Further, this paper describes on the inrush current calculation on composite cores together with the formulae and derived characteristic curves. The results and formulae presented in this paper are verified with laboratory experiments with real transformers, built with composite cores.

Keywords: Composite Core, Inrush Current, Toroidal Transformer, Magnetic Saturation

\section{Introduction}

Inrush current (sometimes called input surge current) is defined as maximum peak current drawn by electrical equipment due to driving its magnetic core into deep saturation at the time of energization. Inrush current is an undesirable phenomenon that has to be taken into consideration where applicable. Elimination of inrush current could be very costly and impossible but mitigation of inrush current is possible [1].

Generally, the inrush current does not last for a long time, but a few cycles of alternative current (See Figure 1). Magnitude of inrush current could be several times the rated current of the equipment, even closer to 30 times in extreme cases, especially with toroidal transformers [2]. The magnitude of the inrush current is based on several parameters like; switching angle, source impedance, magnitude of input voltage, residual flux on the magnetic core, saturation inductance, etc. [3]. As a result, the overcurrent protection reacts for these high currents and trips the device from the source more often, resulting in inability to energize the equipment. Also the inrush current will result in significant voltage drops, and thus affect the power quality, reliability, and stability [2] [4].

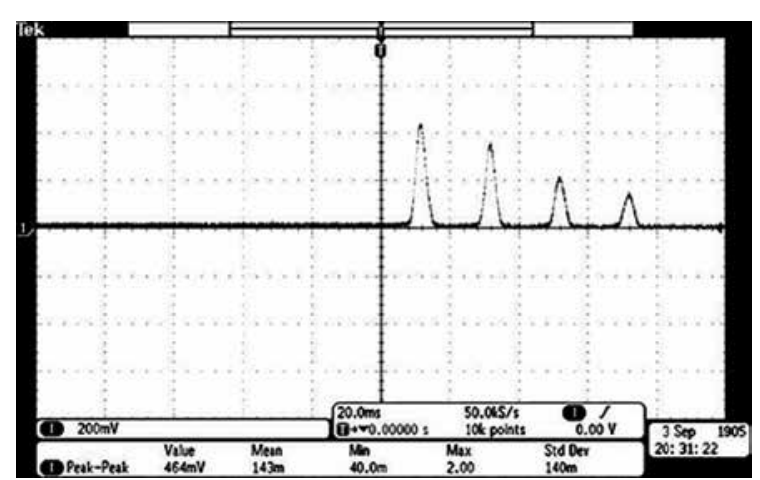

Figure 1 - Inrush Current Transient Waveform

Most of the time the inrush current is harmless to the device but unwanted tripping could cause undue problems to the electrical system [5].

Eng. W.P.T.S. Perera, BSc Eng (Moratuwa), Lead Design Engineer, Noratel International (Pvt) Ltd., Katunayake. Email:sameerap@noratel.lk

Eng. (Prof.) J.P. Karunadasa, BSc Eng (Moratuwa), MSc (Manch), PhD (Manch), CEng, MIE (SL), MIEEE, Associate Professor in Electrical Engineering, University of Moratuwa, Sri Lanka,

Email:karunadasaj@uom.lk

DORCID ID: $h$ ttp://orcid.org/0000-0003-4678-0826

Eng. S.N. De Zoysa, BSc Eng (Peradeniya), Design

Engineer, Noratel International (Pvt) Ltd., Katunayake. Email:Suresh.N@noratel.lk

Eng. M.A.S.C. Wickramasinghe, BSc Eng (Peradeniya), Lead Design Engineer, Noratel International (Pvt) Ltd.,

Katunayake.

Email:SumithW@noratel.lk 
However, the inrush current in toroidal transformers which are normally connected to high end applications involving expensive power electronic equipment will create serious problems and other undesirable issues.

Several solutions external to the toroidal transformers had been proposed for inrush current mitigation such as; use of Negative Temperature Coefficient (NTC) thermistors in primary winding [6], pre-insertion resistors [7], and controlled switching [8]-[10], but all of them will increase the complexity of the system whilst reducing the reliability. Therefore, the robust transformer based solutions are always desirable in the industry [2].

Transformer based solutions such as; the use of low grade (or non-annealed) electrical steel types, introducing air-gaps [11], and reducing the design flux density are always reliable and robust [2][4], but still these options have some drawbacks of being bulkier, higher cost, and most importantly they are compromising typical toroidal performance characteristics significantly. Therefore, the industry still needs a more developed transformer based solution for mitigating the inrush current.

This paper provides a solution for that requirement with composite core concept while preserving the high performance features of the toroidal construction. This paper includes the theoretical background and the design methodology for this concept plus the performance comparison with the conventional air-gap designs. When it comes to the scope of the research, the experiments are done only with the mains input voltage $230 \mathrm{~V}$ for the transformers designed with fixed flux density (considering flux density $1.30 \mathrm{~T}$ for inner uncut core) covering the power range approximately $1 \mathrm{kVA}$ to $5 \mathrm{kVA}$. Also, there are only two steel types considered with defined steel area ratio range describe in the later sections.

\section{Inrush Current}

Inrush current is a transient scenario, where the high saturation of the transformer core originates high inrush current at the point of energization. Basically the input voltage applied to the transformer will be the driving force for the inrush current and that will force the flux to build up double the steady state flux plus the remanence flux [4]. Therefore, the transformer drives into deep saturation condition resulting a high energization current [12]. Theoretically, it can be proved that the maximum inrush current occurs when switched at the zero-crossing of the input voltage wave form due to maximum flux $\left(\Phi_{\max }\right)$ generated in the core, and it is given by equation (1).

$$
\phi_{\max }=2 \phi_{m}+\phi_{r}
$$

where, $\Phi_{m}$ is the peak flux generated in the normal operation and $\Phi_{r}$ is the remanence flux.

\section{Composite Core Concept}

As per the concept of the composite core, there are two cores positioned concentrically; one is uncut core in the centre and the other is a cutcore around the centre core. The basic arrangement is shown in Figure 2 [13].

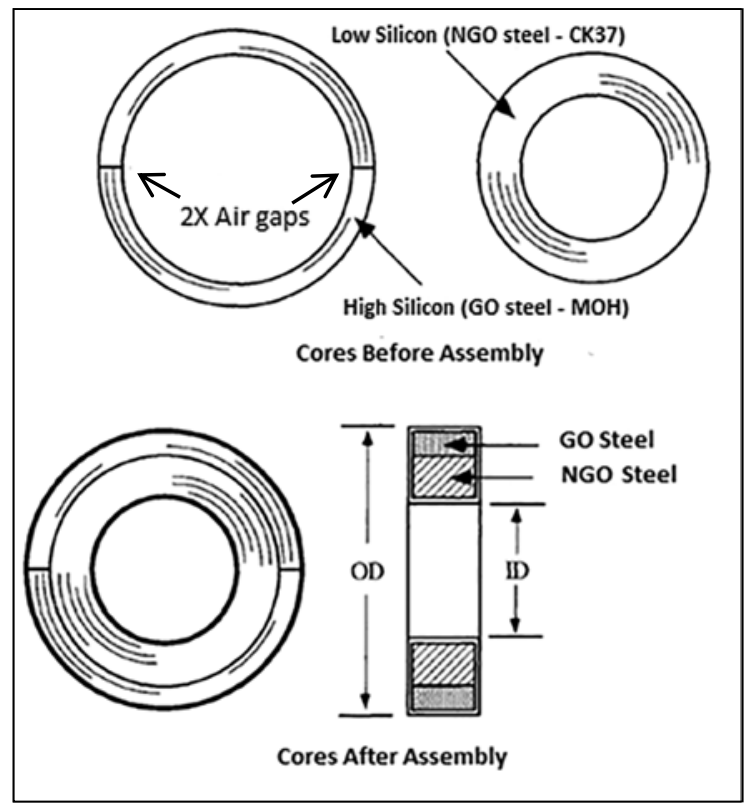

Figure 2 - Composite Core Arrangement

In this core arrangement, the centre core is made with Non Grain Oriented Silicon Steel (NGOSS) type (AISI CK37-35H300) and the outer core is made with Grain Oriented Silicon Steel (GOSS) type (AISI M0H - M103-27P) [14] together with a controlled air-gap.

\subsection{Manufacturing of Composite Core}

In comparison with the conventional cut core construction, there are several advantages with composite core method. The main feature being that it does not need extra attention in core cutting process for a smooth cutting surface. Furthermore, as the outer cut core is not significant in normal operation, the composite core does not need much of a reinforced bonding mechanism like in a conventional core, hence reducing the manufacturing cost. Also the composite core does not need varnishing the total core, so again reducing cost and 
material. See Figures $3 \mathrm{a}$ and $3 \mathrm{~b}$ for composite core and conventional cut core samples.

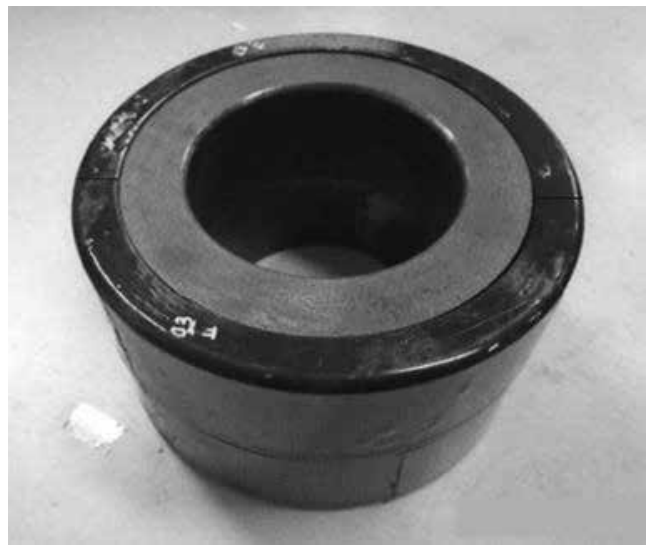

Figure 3a - Composite Core

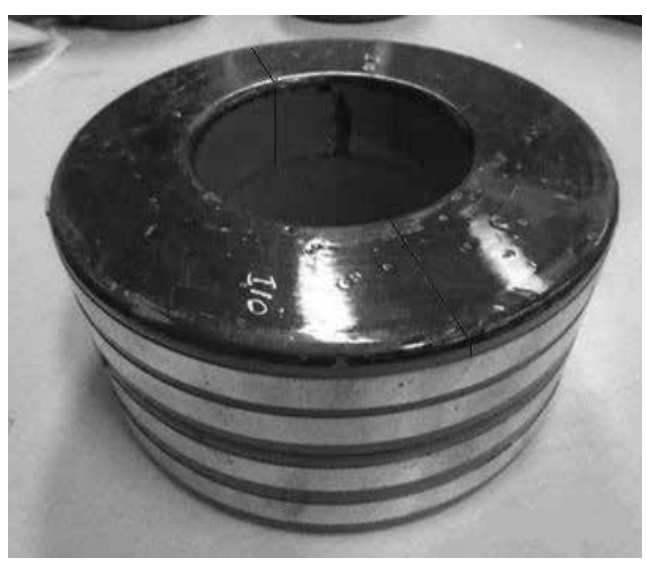

Figure 3b - Conventional Cut Core

\subsection{Experimental Derivations}

According to the basics of magnetism, majority of the flux will concentrate on the path of lower magnetic reluctance. At lower levels of core energization the inner core is unsaturated and the flux is mostly flowing in the inner-core. But at higher core energizations the inner-core gets saturated and the outer-core (which is unsaturated due to the air-gap) takes up more and more of the excess flux. Thus, the centre core will dominate in the normal operation of the transformer, and the outer core (with airgap) will dominate in the inrush current transient. Figure 4 shows the flux density distribution of 1000 VA composite core (between the cut core and uncut core) transformer when it is subjected to deep saturation with respect to normal operating voltage $(230 \mathrm{~V})$.

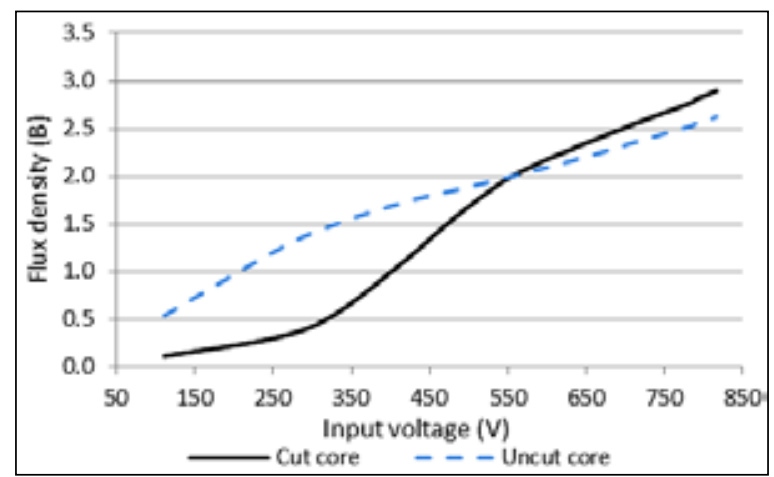

Figure 4 - Flux Density Distribution between Cut Core and Uncut Core

Accordingly, in normal operation condition, the inner core is holding majority flux density approximately $1.20 \mathrm{~T}$, while it is only $0.30 \mathrm{~T}$ in the outer core. But in deep saturation condition (at inrush current transient where the core energized to approximately 2.65 times energization to normal), the outer core dominates at flux density $2.21 \mathrm{~T}$ keeping the composite core unsaturated.

The basic design details of the test sample are given in Table 1, where the core dimensions are shown as; Outer diameter $x$ Inner diameter $x$ Height.

Table 1 - Design Details of the 1000 VA Test Sample

\begin{tabular}{ccccc}
\hline $\begin{array}{c}\text { Cut core } \\
\text { dimensions } \\
(\mathrm{mm})\end{array}$ & $\begin{array}{c}\text { Uncut core } \\
\text { dimensions } \\
(\mathrm{mm})\end{array}$ & $\begin{array}{c}\text { Primary } \\
\text { turns }\end{array}$ & $\begin{array}{c}\text { Primary } \\
\text { resistance } \\
(\Omega)\end{array}$ & $\begin{array}{c}\text { Core } \\
\text { area } \\
\text { ratio }\end{array}$ \\
\hline $165 \times 135 \times 90$ & $133 \times 90 \times 90$ & 433 & 0.745 & 0.7 \\
\hline
\end{tabular}

Air-gap is the main design parameter in the design process with composite core. Equation (2) gives the general relationship between the maximum inrush current and the impedance of the transformer [15] [16].

$$
I_{\max }=\frac{V_{m}}{\sqrt{\left(\omega L_{s}\right)^{2}+R^{2}}} \cdot\left(1+\cos \theta+\frac{B_{s}-B_{r}}{B_{n}}\right)
$$

where, $V_{m}$ is the peak of the voltage, $\omega$ is the angular frequency, $L_{s}$ is the saturation inductance, $R$ is the input winding resistance, $\theta$ is the switching angle, $B_{r}$ is the residual flux density, $B_{s}$ is the saturation flux density, and $B_{n}$ is the nominal design flux density.

According to Equation (2), it is obvious that increasing the impedance ( $L_{s}$ and $R$ ) will be the main option to minimize the inrush current. But in a practical situation, the designer does not have much allowance to change the winding resistance because the product itself should 
comply with a certain thermal class. Hence, changing the winding resistance is not an option to control the inrush current, and therefore increasing $L_{s}$ will be the only option in the design process with the composite core.

Also, as will be seen in Equation (6), reducing the air-gap will increase the inductance value. However, too much reduction of the gap will lead to saturation of the outer core. The outer core dominates in the inrush scenario, so it needs to maintain the outer core unsaturated in the inrush current transient. Therefore, it needs to find the optimum air-gap, which holds the maximum $L_{s}$, while keeping the outer core unsaturated. Figure 5 shows the variation of inrush current with the length of air-gap, obtained by tests.

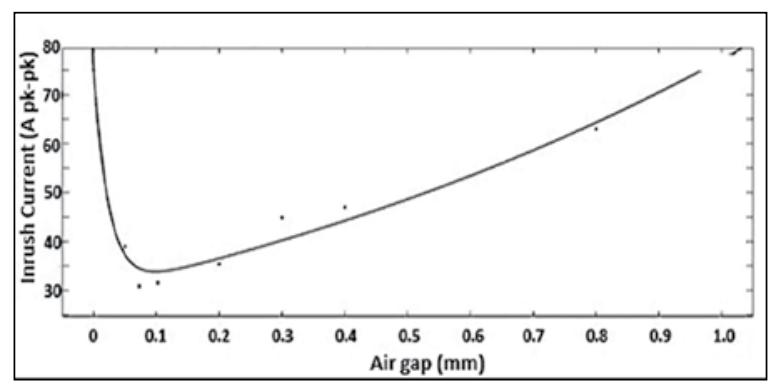

Figure 5 - Variation of Inrush Current with Outer Core Air-Gap

According to Figure 5, a higher inrush current is observed in the lower air-gaps and this is due to the saturation of the outer cut core. As the air-gap increases, the inrush current reduces due to entering the cut-core in to unsaturated region. But too much increase of the air-gap will again increase the inrush current due to the drop of $L_{s}$. Thus, there is a particular air-gap that should be maintained to minimize the inrush current, which is the Optimum air-gap.

It was experimentally found that the optimum air-gap changes with the size of the cut-core cross sectional area (or the power of the transformer). The distribution of optimum airgap with respect to cross sectional area is shown in Figure 6, and accordingly the designer can select the optimum air-gap using this characteristic.

Maintaining the air-gap is critical in composite core scenario, where it may use specially made spacers or commonly available Intek sticky tapes (Class $\mathrm{H}$ graded), with thickness steps $0.05 \mathrm{~mm}$ for cut core construction.

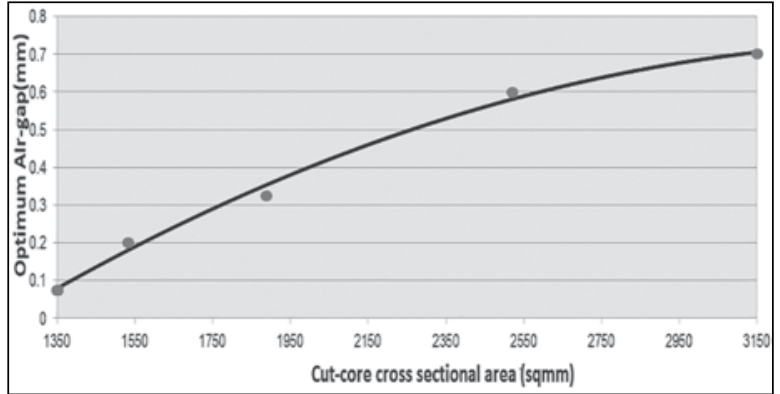

Figure 6 - Optimum Air-Gap to the Cut Core Cross Sectional Area

\section{Inrush Current Calculation}

The proposed inrush current calculation is basically based on Equation (2). Firstly, Equation (2) is simplified for the maximum inrush current at zero crossing $(\theta=0)$ and taking $V_{m}$ as $\sqrt{2} V_{r m s}$.

$$
I_{\max }=\frac{\sqrt{2} V_{r m s}}{\sqrt{\left(\omega L_{s}\right)^{2}+R^{2}}} \cdot\left(2+\frac{B_{s}-B_{r}}{B_{n}}\right)
$$

Together with the BH loop of composite core at normal operation (see Figure 7), it can be proved that the relationship between $B_{r}$ and $B_{s}$ is $B_{r}=0.75 B_{s}$. Also it is proven experimentally that the above ratio is almost constant in the composite cores, irrespective of the air-gap size, unlike conventional total cut-core designs. The reason is the centre uncut core keeps the composite core characteristics unchanged, even with different air-gaps.

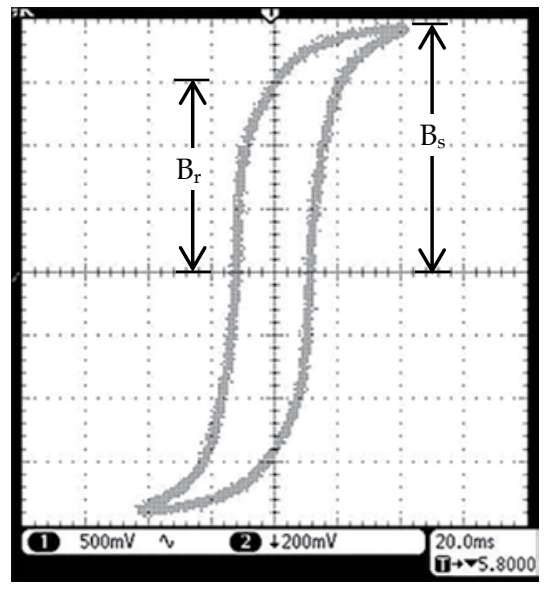

Figure 7 - BH Loop of Composite Core at Normal Operation

Then the composite core is subjected to a deep saturation condition, where it starts saturation near input voltage $610 \mathrm{~V}$ (nominal voltage 230 $\mathrm{V})$. Figure 8 shows the $\mathrm{BH}$ loop of the composite core at the starting point of saturation. Accordingly it can be proved that 
the relationship ratio between $B_{s}$ and $B_{n}$ as $B_{s}: B_{n}=2.65: 1$.

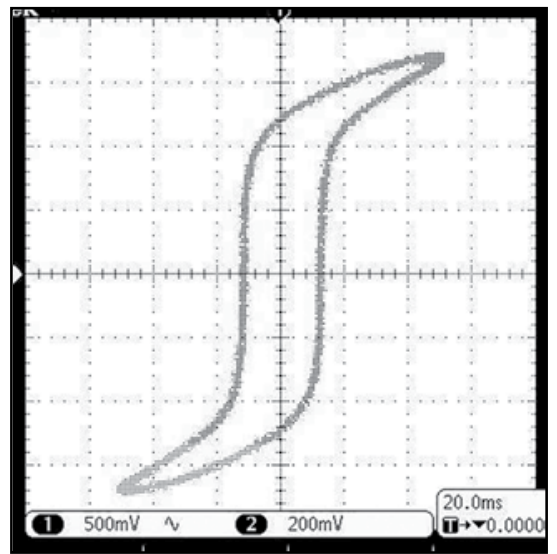

Figure 8 - BH Loop of Composite Core at Saturated Condition

Accordingly it can be proved $\left(B_{s}-B_{r}\right) / B_{n}$ is 0.65 . Then, after substituting the findings in to Equation (3), Equation (4) is obtained.

$$
I_{\max }=\frac{3.75 V_{r \operatorname{ms}}}{\sqrt{\left(\omega L_{s}\right)^{2}+R^{2}}}
$$

\subsection{Calculating Saturation Inductance $L_{s}$}

Here the two cores shall be considered separately in calculating the total $L_{s}$. They are the inductance of the inner core $\left(L_{\text {uncut }}\right)$ and the inductance of the outer core $\left(L_{c u t}\right)$.

The inductance of the inner uncut core can be considered as the inductance of air choke, because the inner core gets saturated at the inrush transient. So $L_{u n c u t}$ will be calculated with Equation (5) considering the value of $\mu_{r}$ as unity.

$$
L_{\text {uncut }}=\frac{4 \pi \times 10^{-7} \cdot N^{2} \cdot A \cdot \mu_{r}}{M P L_{\text {uncut }}}
$$

where, $N$ is the number of turns of primary winding, $A$ is the cross sectional area of inner uncut core, $\mu_{r}$ is the relative permeability of air, and $M P L$ is the mean magnetic path length. Based on the test sample considered, $L_{\text {uncut }}$ is calculated as $1.3 \mathrm{mH}$.

Then the inductance of the outer cut core is calculated from Equation (6).

$$
L_{c u t}=\frac{4 \pi \times 10^{-7} N^{2} A \cdot \mu_{r}}{M P L+\mu_{r} \cdot l_{g}}
$$

where, $A$ is the outer cut core cross sectional area, $\mu_{r}$ is the relative permeability of steel, $l_{g}$ is the air-gap and MPL is the mean magnetic path length of outer cut core. Based on the test sample considered, $L_{c u t}$ is calculated as 71.8 $\mathrm{mH}$.

In this case, the cut core is in an unsaturated condition and the value of $\mu_{r}$ is taken from the B- $\mu$ characteristic curve (which is developed for steel type M0H-M103-27P) of Figure 9, at the time of inrush transient (at $\mathrm{B}=2.21 \mathrm{~T}$ ). Accordingly the value to $\mu_{r}$ is taken as 109.5.

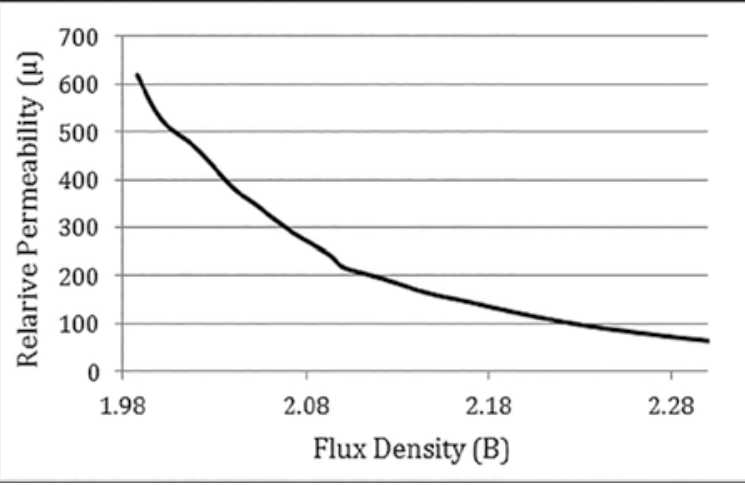

Figure 9 - Calculated B- $\mu$ Characteristic Curve

The total saturation inductance $\left(L_{s}\right)$ is calculated as the summation of the above inductances $\left(L_{\text {uncut }}+L_{c u t}\right)$ as $73.1 \mathrm{mH}$. Accordingly, it is obvious that the effect of the centre uncut core is negligible at the inrush transient scenario.

Then the inrush current is calculated as $38.86 \mathrm{~A}$ which is very close to the laboratory tested inrush current value $36.3 \mathrm{~A}$. The relevant inrush current wave form extracted from laboratory testing is given in Figure 10.

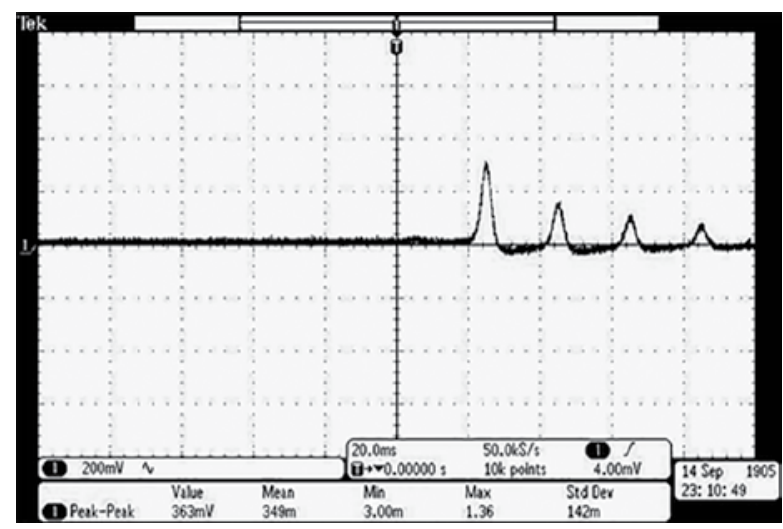

Figure 10 - Inrush Current Wave Form for 1000 VA Transformer

The same testing procedure was applied for the next sizes of the transformers, which were designed following the same optimum air-gap 
curve in Figure 6, the same design flux density, and the same core area ratio. The measured outer core flux density at inrush current transient and the respective relative permeability for each size are shown in Table 2.

Table 2 - Relative Permeability to the Core Cross Sectional Area

\begin{tabular}{lcccc}
\hline $\begin{array}{c}\text { Transformer Cut-core area } \\
\text { Power }\end{array}$ & $\begin{array}{c}\text { Air-gap } \\
\left(\mathrm{mm}^{2}\right)\end{array}$ & $\begin{array}{c}\text { Flux density } \\
(\mathrm{mm})\end{array}$ & of cut core $(\mathrm{B})$ & $\mu_{\mathrm{r}}$ \\
\hline 1000 VA & 1350 & 0.075 & 2.21 & 109.5 \\
\hline $2000 \mathrm{VA}$ & 1890 & 0.30 & 2.15 & 160.0 \\
\hline $3000 \mathrm{VA}$ & 2520 & 0.60 & 2.10 & 220.0 \\
\hline $4500 \mathrm{VA}$ & 3150 & 0.70 & 2.07 & 291.0 \\
\hline
\end{tabular}

Then it is possible to create a direct relationship between the cut-core area and the relative permeability as in Figure 11 (almost linear), which is derived from the samples with constant core area ratio. This characteristic is very useful in the design process as well as in inrush current calculations.

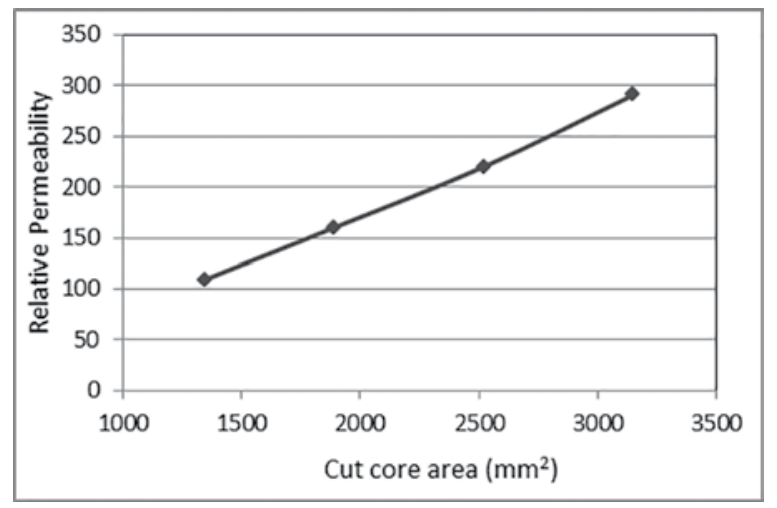

Figure 11 - Relative Permeability Vs Cut-Core Cross-Sectional Area

\section{Calculation of Inrush Current for Different Area Ratios}

The characteristic shown in Figure 11 is valid only for composite cores with cut core to uncut core area ratio $0.7: 1$ at the same design flux density. But to enable inrush current calculation for different area ratios, two design ranges (1000 VA and 3000 VA) were experimentally tested for inrush current, changing the outer cut core area, but keeping all other parameters constant. The relevant test data are tabulated in Table 3.

The steel area ratio over the range 0.6 to 0.8 was considered in this study and it covers the inrush current range approximately 3 to 9 times of load current. This range covers most of the application requirements that come under toroidal transformers.

Table 3 - Inrush Current Measurements for Different Area Ratios

\begin{tabular}{lcc}
\hline \multirow{2}{*}{$\begin{array}{c}\text { Steel area } \\
\text { ratio }\end{array}$} & \multicolumn{2}{c}{ Inrush Current $\left(\mathrm{A}_{\mathrm{pk}-\mathrm{pk}}\right)$} \\
\cline { 2 - 3 } 0.60 & $3000 \mathrm{VA}$ & $1000 \mathrm{VA}$ \\
\hline 0.65 & 120.3 & 72.7 \\
\hline 0.70 & 78.5 & 47.3 \\
\hline 0.75 & 58.9 & 36.3 \\
\hline 0.80 & 47.2 & 28.2 \\
\hline
\end{tabular}

Figure 12 shows the inrush current as a multiple of the load current (rated current) against the steel area ratio for the two transformers tested. Both have almost the same characteristic. Thus, the inrush current calculated for the core area ratio of $0.7: 1$ (as discussed in the previous sections) can be used with this characteristic curve to calculate the inrush currents for different area ratios.

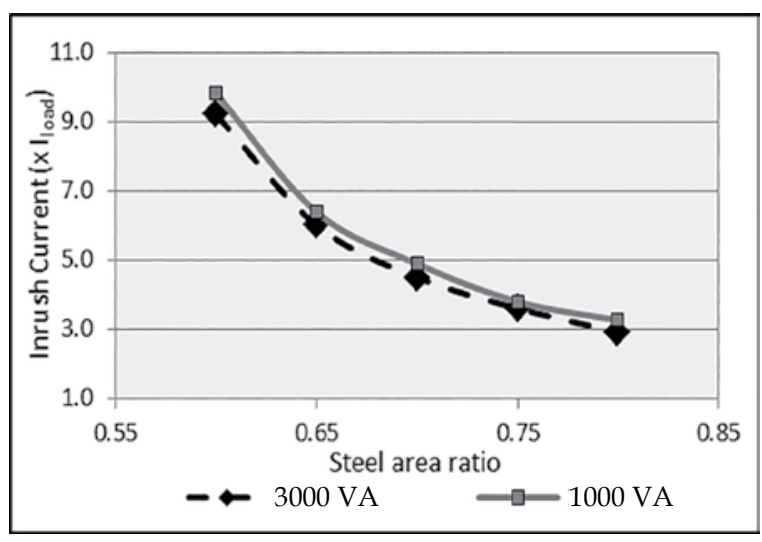

Figure 12 - Inrush Current (x $I_{\text {load }}$ ) Vs Steel Cross-Sectional Area Ratio

The characteristic curve of Figure 12 can be fitted to mathematical Equation (7),

$Y(X)=-690 X^{3}+1582.4 X^{2}-1218.9 X+318.11$

where, $X$ is the core cross sectional area ratio and $Y$ is the inrush current as a multiple of rated current.

Inrush current for a given steel ratio $(X)$ can now be computed in-terms of the inrush current corresponding to steel ratio 0.7 with a 
multiplying factor $Y(X) / Y(0.7)$, denoted as $K_{\text {ratio }}$ for convenience.

$$
\begin{aligned}
K_{\text {ratio }}= & -192.415 X^{3}+441.27 X^{2}-339.905 X+ \\
& 88.709
\end{aligned}
$$

General equation for calculating the maximum inrush current is given by Equation (9).

$$
I_{\max }=\frac{3.75 V_{\text {rms }}}{\sqrt{\left(\omega L_{s}\right)^{2}+R^{2}}} \times K_{\text {ratio }}
$$

In Equation (9), $L_{s}$ and $R$ are inductance and resistance values for the transformer with steel ratio 0.7 , found in Section 4 .

To prove the validity of the inrush current modelling, several test transformers were built and inrush currents measured. Using the developed model inrush current was computed and then compared. Table 4 gives a summary of the results.

Table 4 - Summary of Calculated and Experimental Test Data

\begin{tabular}{lccc}
\hline $\begin{array}{c}\text { Transformer } \\
\text { Power }\end{array}$ & $\begin{array}{c}\text { Measure } \\
\text { inrush current } \\
\left(\mathrm{A}_{\text {pk-pk }}\right)\end{array}$ & $\begin{array}{c}\text { Calculated } \\
\text { inrush current } \\
\left(\mathrm{A}_{\text {pk-pk }}\right)\end{array}$ & $\begin{array}{c}\text { Deviation } \\
\%\end{array}$ \\
\hline 1000 VA & 36.3 & 38.86 & 6.6 \\
\hline 2000 VA & 51.8 & 54.22 & 4.5 \\
\hline 3000 VA & 58.9 & 60.74 & 3.0 \\
\hline 4500 VA & 59.5 & 60.84 & 2.2 \\
\hline
\end{tabular}

The Table confirms that the accuracy of inrush current modelling is within $10 \%$, which is considered quite good.

\section{Conclusion}

This paper has presented the details of the development of silicon steel composite core toroidal transformer to mitigate the inrush current problem. In comparison with other robust transformer based inrush current mitigation methods, the composite core has several advantages.

Comparing with the conventional cut core method, the developed composite core holds considerably lower no load current (and consequently lower reactive power loss) due to its uncut core in the centre. As experimentally found, the composite core can reduce $50 \%$ of no load current and reactive power loss, compared to the same cost corresponding conventional cut core design.
The other advantage over the conventional cut core is that, the composite core has an optimally calculated and controlled air-gap in the outer core. Hence the inrush current estimations based on this model were found to be accurate, well within 10\%, according to test measurements done on a series of test transformers in the range $1 \mathrm{kVA}$ to $5 \mathrm{kVA}$.

Compared with both the conventional cut core and the bulky low flux density designs, the proposed composite core has the opportunity to use recycled steel for the centre uncut core, and hence, to reduce the material cost whilst saving natural resources. Therefore, the proposed transformer based solution is more reliable, economical, simpler to design, and environmental friendly for inrush current mitigation.

\section{Acknowledgement}

Authors wish to acknowledge the support of Noratel International (Pvt) Ltd. and Noratel UK Ltd. by providing facilities and investing in constructing and testing the transformers during the investigations.

\section{References}

1. Ekanayake, H. K., "Methodology to Limit Inrush Current of Toroidal Transformers", Chartered Engineering IESL, 2012.

2. Dogan, R., and Jazebi, S., "Investigation of Transformer-Based Solutions for the Reduction of Inrush and Phase-Hop Currents", IEEE Transactions on Power Electronics, Vol. 31, Issue 5, July 2015, pp 3506 - 3516.

3. Ling, P. C. Y., and Basak, A., "Investigation of Magnetizing Inrush Current in a Single-Phase Transformer", IEEE Trans. Magn., Vol. 24, no. 6, November 1988, pp. 3217-3222.

4. Farazmand, A., de Leon, F., Zhang, K., and Jazebi, S., "Analysis, Modeling, and Simulation of the Phase-Hop Condition in Transformers: The Largest Inrush Currents", IEEE Transactions on Power Del, Vol. 29, no. 4, August 2014, pp 1918 1926.

5. Al-Khalifah, A. K., and EI-Saadany, E. F., "Investigation of Magnetizing Inrush Current in a Single-Phase Transformer", Proc. IEEE Large Engineering Systems Conf. on Power Eng., 2006, pp. 165-171. 
6. Billings, K., and Morey, T., "Switch Mode Power Supply Handbook", Second edition. New York: McGraw Hill, 1989, pp 1-6.

7. Blume, L. F., Camilli, G., Farnham, S. B., and Peterson, H. A., "Transformer Magnetizing Inrush Currents and Influence on System Operation", AIEE Trans. Power App. Syst. Vol. 63, January 1944, pp 366-375.

8. Brunke, J. H., and Frohlich, K. J., “Elimination of Transformer Inrush Currents by Controlled Switching I, Theoretical Considerations", IEEE Trans. Power Del., Vol. 16, no. 2, April 2001, pp 276 -280 .

9. Brunke, J. H., and Frohlich, K. J., “Elimination of Transformer Inrush Currents by Controlled Switching II, Application and Performance Considerations", IEEE Trans. Power Del., Vol. 16, no. 2, April 2001, pp 281 - 285.

10. Reis, A., de Oliveira, J. C., Apolonio, R., and Bronzeado, H. S., "A Controlled Switching Methodology for Transformer Inrush Current Elimination: Theory and Experimental Validation", in Proc. IEEE 11th Int. Conf. on Electrical Power Quality and Utilization, 2011, pp. 16.

11. Gladstone, B., Magnetic Solution: Solving Inrush Current at the Source", Power Electr. Tech., April 2004, pp. 14-26.

12. Francisco de, L., and Brian, G., "Transformer Based Solutions to Power Quality Problems", Plitron Manufacturing Inc. Canada, 2001.

13. Colonel, M. W., and Mclyman, T., "Transformer and Inductor Design Handbook", Third Edition, Kg Magnetics, Inc. California, USA, 2004, pp. 96100.

14. Kawasaki Steel Corporation, "Plasma Core RGHPJ RGH AND RG CORE”, Grain-Oriented Magnetic Steel Strip, Japan: 1991.

15. Jazebi, S., and $\mathrm{Wu}, \mathrm{N} .$, "Enhanced Analytical Method for the Calculation of the Maximum Inrush Current of Single Phase Power Transformer", IEEE Transactions on Power Delivery, Vol. 30, Issue 6, June 2015, pp 2590 - 2599.

16. Wang, Y., and Sami, G., "Analytical Formula to Estimate the Maximum Inrush Current", IEEE Translations on Power Delivery, Vol. 23, no 2, April 2008, pp $1266-1268$. 